\title{
Factors Affecting the Total Cost and Design of the Supply Chain Network
}

\author{
Razaullah $^{1, *}$, Iftikhar Hussain ${ }^{2}$, Shahid Maqsood ${ }^{2}$ \\ and Ishtiaq Ahmad ${ }^{3}$ \\ ${ }^{1}$ Department of Mechanical Engineering, Sarhad University of Science \& IT, \\ Peshawar, Pakistan \\ ${ }^{2}$ Department of Industrial Engineering, University of Engineering \& Technology, \\ Peshawar, Pakistan \\ ${ }^{3}$ PhD Scholar, Department of Management Sciences, Iqra National University, \\ Peshawar, Pakistan \\ *Corresponding Author: raza.me@ suit.edu.pk
}

Received 15 August 2017; Accepted 21 October 2017;

Publication 20 November 2017

\begin{abstract}
The network design determines the physical configuration and infrastructure of the supply chain. An efficient supply chain network design is essential for organizations as it aims to minimize the total cost and the products reach the demand points at lowest cost possible with flexible demand. In order to design the supply chain network, an optimization model is developed with a single objective to minimize the total cost. The model determines the best locations of network nodes to minimize the total cost while satisfying the customer demands. The objective function considers the minimization of transportation cost, production cost and the operational costs for the facilities. The incorporation of budget constraint, delivery mode, cross-route costs, maximum flow by a shipping firm, production capacity of the plants, stocking capacity of distribution centers and traffic factors on the supply routes in the mathematical model further broadened the problem. Computational results for different data sets revealed that the proposed solution approach and mathematical model is effective. Also, it has been demonstrated that the benefits of considering traffic factor, cross-route costs, delivery mode and shipping firm selection during supply chain network design phase are significant.
\end{abstract}

Journal of Industrial Engineering and Management Science, Vol. 1, 241-262. doi: 10.13052/jiems2446-1822.2017.012

This is an Open Access publication. (c) 2017 the Author(s). All rights reserved. 


\section{Razaullah et al.}

Keywords: Cost minimization, Network design, Supply chain, Shipping firm.

\section{Introduction}

A supply chain is a system of activities, individuals, information, organizations, and resources involved in product delivery from origin to destination. The activities in supply chain include the conversion of raw materials into finished products that is moved to the end customer [1]. The evolution of the basic supply chain is the Supply Chain Network (SCN). Because of the rapid technological advancement, a basic supply chain can be advanced by organizations into a more complex structure involving a higher level of interdependence and connectivity between more organizations, this establishes a supply chain network [2]. A supply chain network is utilized to show the materials and information flow across organizations and can also be utilized to highlight interactions between organizations. Supply chain networks are nowadays more global than ever and are typically structured with five main areas: raw material suppliers, production plants, distribution centres, demand points and transportation assets [3].

The supply chain network design task involves which production plants and warehouses to be opened and the design of distribution network to satisfy the customer demand with minimum cost. F. Altiparmak et al. [4] presented a solution technique which was based on steady-state genetic algorithms with a novel encoding structure for the design of a multi-product, single-source, multi-stage supply chain network. The effectiveness of the steady-state genetic algorithms was examined by comparing its outcomes with those attained by Lagrangian heuristic, hybrid genetic algorithm and simulated annealing on a set of supply chain network design problems with different sizes. Supply chain network is associated with planning, coordination and control of raw materials and final products. Efficient SCM is important in a competitive market which needs an on-time delivery under low inventory to meet customer orders at the lowest cost. The objective of the model presented by B.K. Lee et al. [5] was to minimize supply chain costs such as replenishment, inventory holding and transportation costs. A. Nagurney [6] proposed a framework for supply chain network design and redesign that allowed the determination of the optimal levels of capacity and operational product flows associated with supply chain activities of manufacturing, storage and distribution at minimal total cost and subject to the satisfaction of customer demands. 
S.H. Lashine et al. [7] presented an integrated model warehouse location, allocation of customers to the selected warehouses and to find the number of transport vehicles for the delivery of the required demand and the vehicle routing in a way to minimize the total cost. The model was formulated as a MILP model and was solved using Lagrange relaxation. To increase profit, many organizations concentrate on decreasing costs in their supply chains. Organization needs to identify how to measure the costs in their supply chains to decrease the total costs. A.I. Pettersson [8] studied measuring supply chain costs with emphasis on how measurements of supply chain costs can be and are used in business. A model was suggested for the measurement of supply chain cost. To identify the difference between supply chain cost based on predicted cost compared to actual cost was also the focus. C.J. Vidal et al. [9] presented a model for the optimization of a worldwide supply of a multinational company that maximized the profits. The presented model also considered the selection of shipping modes. The computational examples showed satisfactory results with close gaps between the local solutions found by the technique and their matching upper bounds. A. Nagurney et al. [10] developed a supply chain model in which the manufacturing plants were producing homogenous product with associated distinct environmental emissions. It was proved that the environmental concerned supply chain model can be formulated and solved as an elastic demand transportation network equilibrium problem. Y. Xiao et al. [11] considered supply chains of fresh products in which the transportation of products was needed by the upstream producer from a production point to a retail market. A supply chain consisting of a single producer and distributor was considered and the push and pull business models were investigated. L. Cui et al. [12] presented the joint replenishment delivery (JRD) model for the improvement delivery process. Under the multi-product environments, joint replenishment is the most preferred consideration in the replenishment process. Joint replenishment is very critical to multinational companies which aim to establish stable supply systems worldwide. Cost and customer satisfaction are the two main factors in the business world. M. Miranbeigi et al. [13] formulated current processes with work-in-process products in a multi-echelon and multi-product supply chain as an updated discrete time dynamic model. The presented model composed of a supplier of raw material, two production facilities of products of two types, one central and two local warehouses, four customers and communication channels. The distribution centers are a critical part of every supply and distribution network of retailer and denote 


\section{Razaullah et al.}

a substantial portion of the over-all cost of logistics. By using automation, there is a growing interest among retailers to enhance the productivity and decrease the cost of distribution center operations. V.K. Dubey et al. [14] presented a framework for sizing an automated distribution center. The discrete event simulation was employed as a tool for modelling and analysis of an aggregate level. The tools and results were used by retailers for making size estimates for equipment, trade-off between equipment and for the layout design of distribution center. K. Matsui [15] investigated the optimal strategy for product distribution for a manufacturer that used dualchannel supply chains. Two symmetric manufacturers were assumed facing price competition which were distributing products in three ways: through retail channel only, through direct channel only and through both retail and direct channels.

Various factors affect the total cost of the supply chain network. The factors such as production capacities of the production facilities, maximum number of products assigned to a shipping firm in a given range for delivery across network nodes, stocking capacities of the warehouses and traffic factor either increase or decrease the total cost of the supply chain network. In this paper, the impacts of these factors on the total cost and design of the supply chain network are analyzed in details.

The rest of the article is organized as follows. In Section 2, the problem statement is presented. In Section 3, an integer mathematical formulation is presented to solve a problem. In Section 4, the impacts of various factors on the total cost of the supply chain network are calculated. Section 5 includes conclusion and suggested areas for further research.

\section{Problem Statement}

One of the goal of supply chain network design is to develop a mathematical modeling framework to design and optimize a supply chain network for product distribution. The levels of supply chain network for product distribution are: supply of raw materials to production plants, supply of finished or semi-finished products to distribution centers and supply of finished products to demand points. If required, then the semi-finished and finished products can be stocked in a warehouse before distribution centers. The processes of supply chain network are: raw materials conversion to finished or semifinished products in production plants, stocking the products in warehouses, transportation of raw materials and products between the nodes of the 


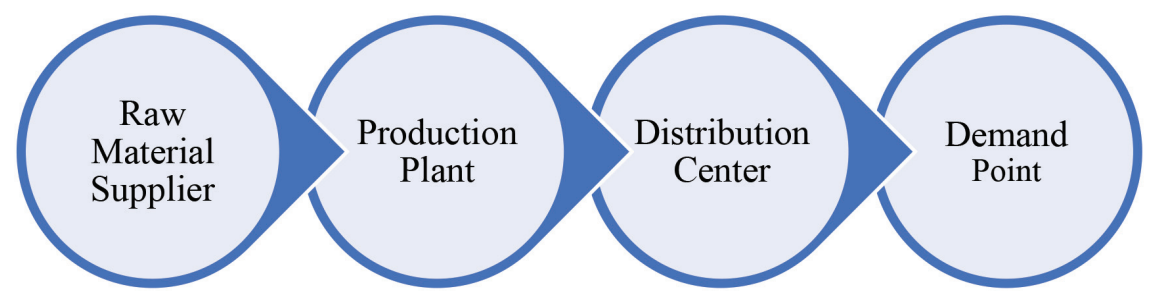

Figure 1 Structure of the supply chain.

network and supply of completed products to demand points from distribution centers. Figure 1 shows a schematic structure of the supply chain for product distribution.

In order to design the supply chain network, an optimization model is developed with a single objective to minimize the total cost. The model determines the best locations of the production plants, warehouses and distribution centers to maximize the profit, minimize the total cost while satisfying the customer demands. The model also specifies: the amount of raw materials transported to production plants, the number of products transported from production plants to warehouses or distribution centers as well as the number of products shipped to the demand points. In this paper, the impacts of various factors: production capacities of production plants, maximum number of products assigned to a shipping firm for flow across network nodes, stocking capacities of warehouses and traffic factor values of the supply routes, are analyzed.

\section{The Mathematical Model}

The mathematical model comprises of all the factors which impact the total cost of the supply chain network. In this broad supply chain network design and optimization problem, the focus is on the location and capacity allocation of production facilities and warehouses. Customers are then assigned to the selected warehouses. In general, the fully flexible supply chain network problem is used to determine the optimum quantity of products shipped from production facilities to the demand points through warehouses and to find the best delivery routes for the delivery of products to fulfill the customer demands at minimum total cost. Before presenting the problem formulation, the following notations are introduced: 


\section{Indices:}

$\begin{array}{lll}c & \text { index of shipping firm } & c=1,2, \ldots, a \\ d & \text { index of discount range } & d=1,2, \ldots, b \\ e & \text { index of product grade } & e=1,2, \ldots, p \\ f & \text { index of production node } & f=1,2, \ldots, q \\ g & \text { index of warehouse node } & g=1,2, \ldots, r \\ h & \text { index of retailer node } & h=1,2, \ldots, s\end{array}$

\section{Parameters:}

$B \quad$ allocated budget for the supply chain for a specific time horizon

$C_{f g} \quad$ cost per unit per mile from production facility $f$ to warehouse $g$

$C_{g h} \quad$ cost per unit per mile from warehouse $g$ to demand point $h$

$D_{f g} \quad$ distance in miles from production facility $f$ to warehouse $g$

$D_{g h} \quad$ distance in miles from warehouse $g$ to demand point $h$

$O_{e f} \quad$ operating cost of locating a production facility at location $f$ to produce product $e$

$O_{e g} \quad$ operating cost of locating a stocking facility at location $g$ to stock product $e$

$F_{f} \quad$ fixed cost of a production facility at location $f$

$F_{g} \quad$ fixed cost of a stocking facility at location $g$

$K_{e f}$ capacity of the production facility $f$ to produce product $e$

$K_{e g} \quad$ capacity of the stocking facility $g$ to stock product $e$

$P_{c d} \quad$ percent discount offered by shipping frim $c$ for discount rang $d$

$R_{e h} \quad$ number of products of grade $e$ required at the demand point $h$

$T_{f g} \quad$ traffic factor value on the route from production facility $f$ to warehouse $g$

$T_{g h}$ traffic factor value on the route from warehouse $g$ to demand point $h$

$W_{e f} \quad$ working days per month of the production facility $f$ to produce product $e$

$H_{e f}$ production time per day of production facility $f$ to produce product $e$ $M_{c} \quad$ percent discount or extra charge by a shipping firm $c$

$l_{d}^{c} \quad$ lower bound on product flow by shipping firm $c$ for discount range $d$

$u_{d}^{c} \quad$ upper bound on product flow by shipping firm $c$ for discount range $d$

$r_{f}^{e} \quad$ production rate at plant $f$ for product of grade $e$

$t_{f}^{e} \quad$ production time at plant $f$ for product of grade $e$

\section{Decision variables:}

$X_{e f g}^{c d} \quad$ number of products of grade $e$ shipped from production node $f$ to stocking node $g$ by the shipping firm $c$ in a discount range $d$ 
$X_{e g h}^{c d} \quad$ number of products of grade $e$ shipped from stocking node $g$ to demand node $h$ by the shipping firm $c$ in a discount range $d$

$Y_{e f} \quad 1$ if production facility producing product $e$ is operated at location $f$, otherwise 0

$Y_{e g} \quad 1$ if stocking facility stocking product $e$ is operated at location $g$, otherwise 0

$z_{d}^{c} \quad 1$ if total product flow shipped by shipping firm $c$ is in the discount range $d$, otherwise.

The problem is formulated as the following integer program:

\section{Minimize:}

$$
\begin{aligned}
Z= & \sum_{f=1}^{q} F_{f}+\sum_{g=1}^{r} F_{g}+\sum_{e=1}^{p} \sum_{f=1}^{q} O_{e f} Y_{e f}+\sum_{e=1}^{p} \sum_{g=1}^{r} O_{e g} Y_{e g}+ \\
& +\sum_{c=1}^{a} \sum_{d=1}^{b} \sum_{e=1}^{p} \sum_{f=1}^{q} \sum_{g=1}^{r} \frac{D_{f g}}{T_{f g}} C_{f g} X_{e f g}^{c d}\left(1-P_{c d}\right)\left(1 \pm M_{c}\right)+ \\
& +\sum_{c=1}^{a} \sum_{d=1}^{b} \sum_{e=1}^{p} \sum_{g=1}^{r} \sum_{h=1}^{s} \frac{D_{g h}}{T_{g h}} C_{g h} X_{e g h}^{c d}\left(1-P_{c d}\right)\left(1 \pm M_{c}\right)
\end{aligned}
$$

The objective function being the total cost of the supply chain network is required to be minimized subject to the following constraints:

$$
\begin{aligned}
& \sum_{f=1}^{q} F_{f}+\sum_{g=1}^{r} F_{g}+\sum_{e=1}^{p} \sum_{f=1}^{q} O_{e f} Y_{e f}+\sum_{e=1}^{p} \sum_{g=1}^{r} O_{e g} Y_{e g}+ \\
& \quad+\sum_{c=1}^{a} \sum_{d=1}^{b} \sum_{e=1}^{p} \sum_{f=1}^{q} \sum_{g=1}^{r} \frac{D_{f g}}{T_{f g}} C_{f g} X_{e f g}^{c d}\left(1-P_{c d}\right)\left(1 \pm M_{c}\right)+ \\
& \quad+\sum_{c=1}^{a} \sum_{d=1}^{b} \sum_{e=1}^{p} \sum_{g=1}^{r} \sum_{h=1}^{s} \frac{D_{g h}}{T_{g h}} C_{g h} X_{e g h}^{c d}\left(1-P_{c d}\right)\left(1 \pm M_{c}\right) \leq B \\
& \quad \forall c \in a, d \in b, e \in p, f \in q, g \in r, h \in s \\
& \sum_{c=1}^{a} \sum_{d=1}^{b} \sum_{g=1}^{r} X_{e g h}^{c d} \geq R_{e h} \quad \forall e \in p, h \in s \\
& \sum_{c=1}^{a} \sum_{d=1}^{b} \sum_{e=1}^{p} \sum_{f=1}^{q} X_{\text {efg }}^{c d}-\sum_{c=1}^{p} \sum_{d=1}^{r} \sum_{e=1} \sum_{h=1}^{s} X_{e g h}^{c d} \geq 0 \quad \forall g \in r
\end{aligned}
$$




$$
\begin{aligned}
& \sum_{e=1}^{p} \sum_{f=1}^{q} \sum_{g=1}^{r} X_{e f g}^{c d}+\sum_{e=1}^{p} \sum_{g=1}^{r} \sum_{h=1}^{s} X_{e g h}^{c d} \geq l_{d}^{c} z_{d}^{c} \quad \forall c \in a, d \in b \\
& \sum_{e=1}^{p} \sum_{f=1}^{q} \sum_{g=1}^{r} X_{e f g}^{c d}+\sum_{e=1}^{p} \sum_{g=1}^{r} \sum_{h=1}^{s} X_{e g h}^{c d} \leq u_{d}^{c} z_{d}^{c} \quad \forall c \in a, d \in b \\
& \sum_{c=1}^{a} \sum_{d=1}^{b} \sum_{e=1}^{p} \sum_{g=1}^{r} X_{e f g}^{c d} \leq K_{e f} Y_{e f} \quad \forall f \in q \\
& \sum_{c=1}^{a} \sum_{d=1}^{b} \sum_{e=1}^{p} \sum_{f=1}^{q} X_{e f g}^{c d} \leq K_{e g} Y_{e g} \quad \forall g \in r \\
& \sum_{c=1}^{a} \sum_{d=1}^{b} \sum_{e=1}^{p} \sum_{h=1}^{s} X_{e g h}^{c d} \leq K_{e g} Y_{e g} \quad \forall g \in r \\
& t_{f}^{e}=r_{f}^{e} \sum_{c=1}^{a} \sum_{d=1}^{b} \sum_{g=1}^{r} X_{e f g}^{c d} \quad \forall e \in p, f \in q \\
& K_{e f}=\frac{W_{e f} H_{e f}}{r_{f}^{e}} \quad \forall e \in p, f \in q \\
& X_{\text {efg }}^{c d}, X_{\text {egh }}^{c d} \geq 0 \text {, integers } \quad \forall c \in a, d \in b, e \in p, \\
& f \in q, g \in r, h \in s \\
& \sum_{d=1}^{b} z_{d}^{c} \leq 1 \\
& \forall c \in a \\
& z_{d}^{c} \in\{0,1\} \\
& \forall c \in a, d \in b \\
& Y_{\text {ef }}, Y_{\text {eg }} \in\{0,1\} \\
& \forall e \in p, f \in q, g \in r
\end{aligned}
$$

Simplex method for linear programming is used to solve the supply chain network problem. The objective of the problem minimizes the fixed and operating costs of the production facilities, fixed and operating costs of the stocking facilities and total shipping cost of the network priced according to the cost per unit per mile times the corresponding distance divided by the traffic factor value times one minus the discount offered for a given range 
of products by a shipping firm times discount or extra charge applied by a shipping firm.

The constraint (1) states that the total customer demand must be satisfied within the allocated budget for the supply chain. The constraint (2) enforces that the customer demand for a specific product must be satisfied at a demand location. The constraint (3) specifies that the total inflow of a specific product to a warehouse must be greater than or equal to the total outflow of that product from the warehouse. The constraint (4) requires that the total flow of products across all routes and all stages of the supply chain network by a shipping firm in a given range is either zero or satisfies the lower bounds of the range whereas the constraint (5) shows that the total flow of products across all routes and all stages of the supply chain network by a shipping firm in a given range is either zero or satisfies the upper bounds of the range. The constraint (6) ensures that the number of products shipped from a production plant to warehouses cannot exceed the production capacity of the plant while the constraint (7) requires that the number of products shipped from production plants for stocking in a warehouse should be less than or equal to the stocking capacity of a warehouse. The constraint (8) enforces that the product outflow from a warehouse should not exceed the stocking capacity of the warehouse. The Equation (9) states that the production time in a plant to produce a product is equal to the production rate times the number of products produced. The Equation (10) states that the capacity of a production plant is equal to the total production time in a specific time horizon divided by the production rate to produce a product while the constraint (11) ensures that the number of products shipped from production facilities to warehouses or from warehouses to demand locations in the supply chain network is both greater than or equal zero and integers. The constraint (12) specifies that the movement of products on all arcs of the network by a shipping firm corresponds to exactly one flow range whereas the constraint (13) enforces that $z_{r}^{c}$ is equal to 1 if total flow of products shipped by firm $a$ is in the range $b$, else 0 . And the last constraint (14) states that each production facility to produce a specific product is either open or close.

\section{Factors Affecting the Total Cost of the Supply Chain Network}

The impacts of various factors on the total cost and design of the supply chain network are analyzed in the following sections one by one. 


\subsection{The Impact of the Production Capacities of the Production Facilities on the Total Cost}

Facility location decision have a long-term impact on the performance of a supply chain because it is expansive to shut down a facility or move it to a different location. A good location decision can help a supply chain be responsive while keeping its costs low. The location of production facilities close to the warehouses or retailers is preferred as it decreases the transportation cost. Building too many production facilities increases the total cost (capital investment). If a single production facility or a set of production facilities cannot satisfy a total customer demand in a given time then additional production facilities are made operational to fulfill the customer demand. Less number of production facilities are required for the fulfillment of customer demand if it has a high production rate of a required product. Also, less number of production facilities are required for the fulfillment of customer demand if the production facilities run overtime and vice versa.

A local paper mill produces the required products of different grades. Customer demands are for master reels of standard width. The production plant 1 has production rates of $1.5 \mathrm{hr} /$ product and $1.0 \mathrm{hr} /$ product to produce products $\mathrm{A}$ and $\mathrm{B}$, respectively. The cost per product at production plant 1 is $\$ 20 /$ product and $\$ 30 /$ product while producing product $\mathrm{A}$ and $\mathrm{B}$, respectively. Similarly, the production plant 2 produces product A and B with production rates of 1.4 and $1.3 \mathrm{hr} /$ product and $\$ 20$ and $\$ 30 /$ product cost rate. The plant production times per day are 15, 16, 17, 18, 19, 20, 21, 22, 23 and 24 hours and is same for both production facilities in case number 1, 2, 3, 4, 5, 6, 7, 8,9 and 10, respectively. The production days per month are 25 for both the plants. The operating expenses of production facility 1 for product A and B each is $\$ 1000$ and $\$ 1200$ each to produce product A and B at production facility 2. The operating expenses of the owned warehouse at node 3 is $\$ 500$ each for stocking product A and B. Similarly, the operating costs of the rented warehouse at node 4 is $\$ 400$ each for stocking product A and B. The fixed costs of production facilities 1 and 2 are $\$ 500$ and $\$ 600$, respectively. The fixed costs of warehouses at nodes 3 and 4 are $\$ 500$ and $\$ 800$, respectively in the given time limit. The stocking capacities of warehouse at node 3 in the given time horizon are 500 and 400 products of grade A and B, respectively. Similarly, the stocking capacities of warehouses at node 4 in the given time horizon are 800 and 700 products of grade $\mathrm{A}$ and $\mathrm{B}$, respectively. The costs, capacities and demands of each node of the supply chain network are shown in Figure 2. The total budget for all expenses is $\$ 125000$. 

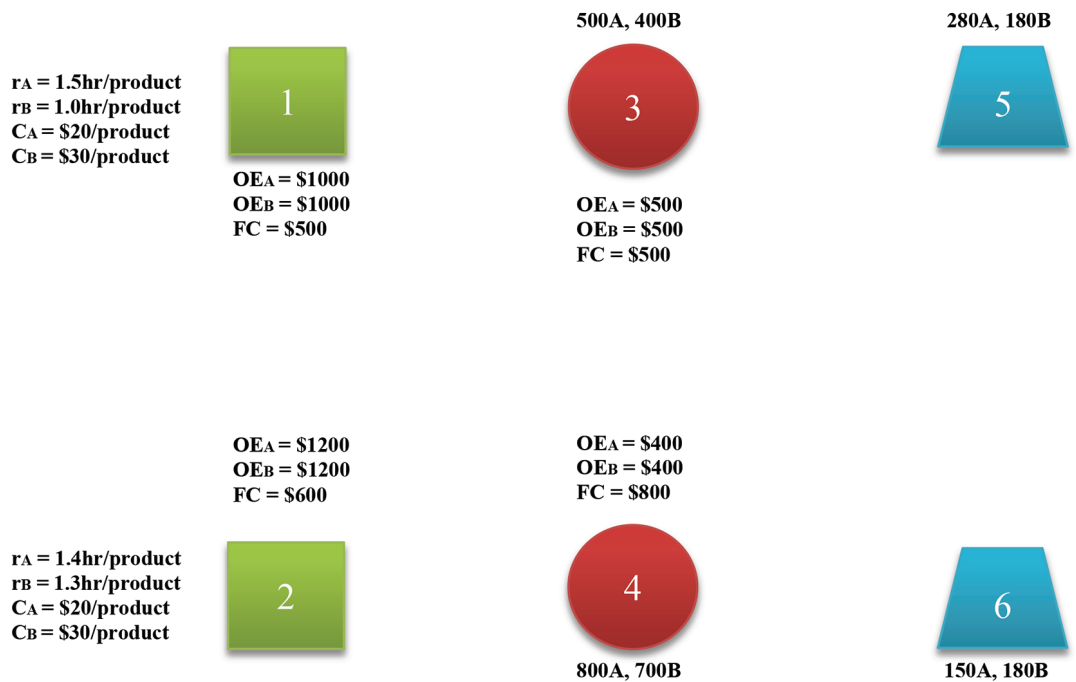

$O E_{A}=\$ 400$ OEB $=\$ 400$ $\mathbf{F C}=\$ 800$ $=1.3 \mathrm{hr} /$ product $\mathrm{C}_{\mathrm{A}}=\$ 20 /$ product

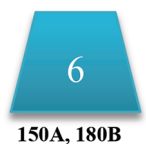

Plant

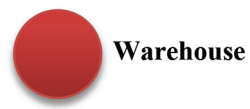

Customer

Figure 2 Costs, demands and capacities of the supply chain network nodes.

Table 1 Impact of production capacity on total cost

\begin{tabular}{llllllcc}
\hline & \multicolumn{2}{c}{ Product A } & & \multicolumn{3}{c}{ Product B } & \\
\cline { 2 - 3 } Case No. & $K_{1}$ & $K_{2}$ & & $K_{1}$ & $K_{2}$ & Total Capacity & Total Cost (\$) \\
\hline 1 & 250 & 267 & & 375 & 288 & $517 \mathrm{~A}, 663 \mathrm{~B}$ & 88010 \\
2 & 266 & 285 & & 400 & 307 & $551 \mathrm{~A}, 707 \mathrm{~B}$ & 87718 \\
3 & 283 & 303 & & 425 & 326 & $586 \mathrm{~A}, 351 \mathrm{~B}$ & 87431 \\
4 & 300 & 321 & & 450 & 346 & $621 \mathrm{~A}, 769 \mathrm{~B}$ & 87137 \\
5 & 316 & 339 & & 475 & 365 & $655 \mathrm{~A}, 840 \mathrm{~B}$ & 85489 \\
6 & 333 & 357 & & 500 & 384 & $690 \mathrm{~A}, 884 \mathrm{~B}$ & 85349 \\
7 & 350 & 375 & & 525 & 403 & $725 \mathrm{~A}, 928 \mathrm{~B}$ & 85210 \\
8 & 366 & 392 & & 550 & 423 & $758 \mathrm{~A}, 973 \mathrm{~B}$ & 85078 \\
9 & 383 & 410 & & 575 & 442 & $793 \mathrm{~A}, 1017 \mathrm{~B}$ & 84939 \\
10 & 400 & 428 & & 600 & 461 & $828 \mathrm{~A}, 1061 \mathrm{~B}$ & 84534 \\
\hline
\end{tabular}

Table 1 shows varying capacities of production facilities for product $\mathrm{A}$ and $\mathrm{B}$. The impact of production capacities on the total cost is analyzed for 280 products of type A plus 180 products of type B at the demand point 1 and 150 products of type A plus 180 products of type B at demand point 2 . The demand time for the whole order from the customers is 25 working days. 
Table 2 Distances, traffic factor values and shipping costs

\begin{tabular}{cccccc}
\hline$D_{f g}$ & Distance (Miles) & $T_{f g}$ & Traffic Factor & $C_{f g}$ & $\$$ Per Unit Per Mile \\
\hline$D_{13}$ & 40 & $T_{13}$ & 0.90 & $C_{13}$ & 2.0 \\
$D_{14}$ & 15 & $T_{14}$ & 0.90 & $C_{14}$ & 2.0 \\
$D_{23}$ & 04 & $T_{23}$ & 0.90 & $C_{23}$ & 2.0 \\
$D_{24}$ & 28 & $T_{24}$ & 1.00 & $C_{24}$ & 1.5 \\
$D_{35}$ & 57 & $T_{35}$ & 1.00 & $C_{35}$ & 1.5 \\
$D_{36}$ & 19 & $T_{36}$ & 0.85 & $C_{36}$ & 2.1 \\
$D_{45}$ & 33 & $T_{45}$ & 1.00 & $C_{45}$ & 2.1 \\
$D_{46}$ & 45 & $T_{46}$ & 1.00 & $C_{46}$ & 2.0 \\
\hline
\end{tabular}

No extra charge on delivery is applied while shipping the products across network arcs i.e., the product delivery is normal. The production plantwarehouse and warehouse-retailer distances, traffic factor values on the supply routes and shipping costs are summarized in Table 2. The distances in miles, traffic factor values and cost per unit per mile are given in second, fourth and sixth columns of Table 2, respectively.

At least one and maximum two available shipping firms may involve in the delivery of customer demands. In Table 3, the discounts offered for different flow ranges by the shipping firms are shown. There is $2 \%$ discount from shipping firm 1, if it is assigned less than 500 units of product-flow across all routes in total. If the total flow assigned to shipping firm 1 is 500 or more but less than 1000, there is $5 \%$ discount on product-flow across all routes in total. The discounts offered for the same ranges of product flow by shipping firm B, are 3 and $6 \%$, respectively. In this case study, the two different product flow ranges are same for both the firms. This is only for simplicity and these ranges may differ from one another for the shipping firms.

Ten different cases have been solved with the date given above. Using LPSolve IDE - 5.5.2.0, the results are evaluated. It is clear that with the increase in production per day of the required products, the total cost decreases. Less number of facilities are required if the production per day is increased. The results are plotted in Figure 3. Increasing the production of a required product at a facility decreases or ceases the production in another production facility. As the production of a product at a facility is ceased, the operating expenses of the required product at that production facility equal to zero. Hence, less

Table 3 Discounts offered for different flow ranges

\begin{tabular}{llcc}
\hline S. No. & Range & Shipping Firm 1 & Shipping Firm 2 \\
\hline 1 & $0-449$ & $2 \%$ & $3 \%$ \\
2 & $500-1000$ & $5 \%$ & $6 \%$ \\
\hline
\end{tabular}




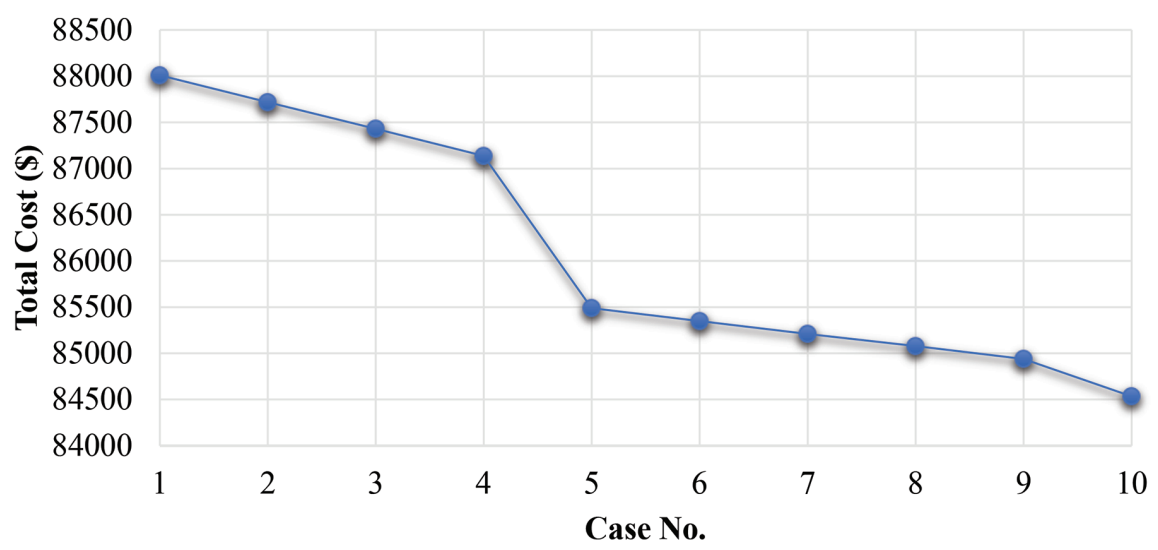

Figure 3 The impact of production capacity on total cost.

number of production facilities are preferred for the fulfillment of the total customer demand.

\subsection{The Impact of the Maximum Number of Products Assigned to a Shipping Firm in a Range for Delivery Across Network Nodes}

The maximum number of products assigned to a shipping firm in a range for delivery across the network nodes affects the total cost of the supply chain network. Ten cases are solved to analyze the impact of the different ranges of products on the total cost. All the cases are solved for 20 working hours per day and 25 working days per month. The production rates, stocking capacities, operating costs, fixed costs and customer demands are same as shown in Figure 2. Also, the distances between the different nodes, traffic factor values and transportation costs are considered same as Table 2 above. In all the cases considered, there is enough budget to cover all the expenses. The demand time from the customer to deliver the finished product is 25 working days.

In the different flow ranges, the discount offered by the shipping firms are considered same as shown in Table 3 above. The maximum number of products assigned to shipping firm in a range for delivery is shown in Table 4. There is 2\% discount from shipping firm 1 for the first range and 5\% discount for the second range. Similarly, there is 5\% discount from shipping firm 2 for the first range and 6\% discount for the second range. The ranges of products are same for both the shipping firms. This is only for simplicity and these ranges may vary. 
Table 4 Flow ranges for the shipping firms

\begin{tabular}{cccc}
\hline & \multicolumn{2}{c}{ Range of Products } & \\
\cline { 2 - 3 } Case No. & Lower Limit & Upper Limit & Total Cost $(\$)$ \\
\hline 1 & 0 & 499 & 85342 \\
& 500 & 1100 & \\
2 & 0 & 599 & 85351 \\
& 600 & 1200 & \\
3 & 0 & 699 & 85360 \\
& 700 & 1300 & \\
4 & 0 & 799 & 85362 \\
& 800 & 1400 & \\
5 & 0 & 899 & 85326 \\
& 900 & 1500 & \\
6 & 0 & 999 & 85298 \\
& 1000 & 1600 & \\
7 & 0 & 1099 & 85298 \\
& 1100 & 1700 & \\
8 & 0 & 1199 & 85298 \\
& 1200 & 1800 & \\
9 & 0 & 1299 & 85298 \\
& 1300 & 1900 & \\
10 & 0 & 1399 & 85298 \\
& 1400 & 2000 & \\
\hline
\end{tabular}

To minimize the total cost, products are assigned to a shipping firm which provides greater discount for a given range of products. Figure 4 shows the impact of flow ranges of products on the total cost. Using LP-Solve IDE 5.5.2.0, the results are evaluated. In all cases, shipping firm 2 in the range 2 is involved to transport the products from production point to the demand point. The total number of products to be transported in the network is 1598 . In cases 1 to 5 , the upper bound of the shipping firm 2 is less than 1598 . So, one additional shipping firm along with shipping firm 2 is required to deliver the products. In cases 6 to 10, the upper bound of the shipping firm 2 is greater than 1600, so only shipping firm 2 delivers the products in the supply chain network as this shipping firm offers greater discount than shipping firm 1.

\subsection{The Impact of the Stocking Capacities of Warehouses on the Total Cost}

The stocking capacities of the warehouses affects the total cost of the supply chain network. The warehouses should have capacities greater than or equal to the total customer demand. The products are manufactured in the production 


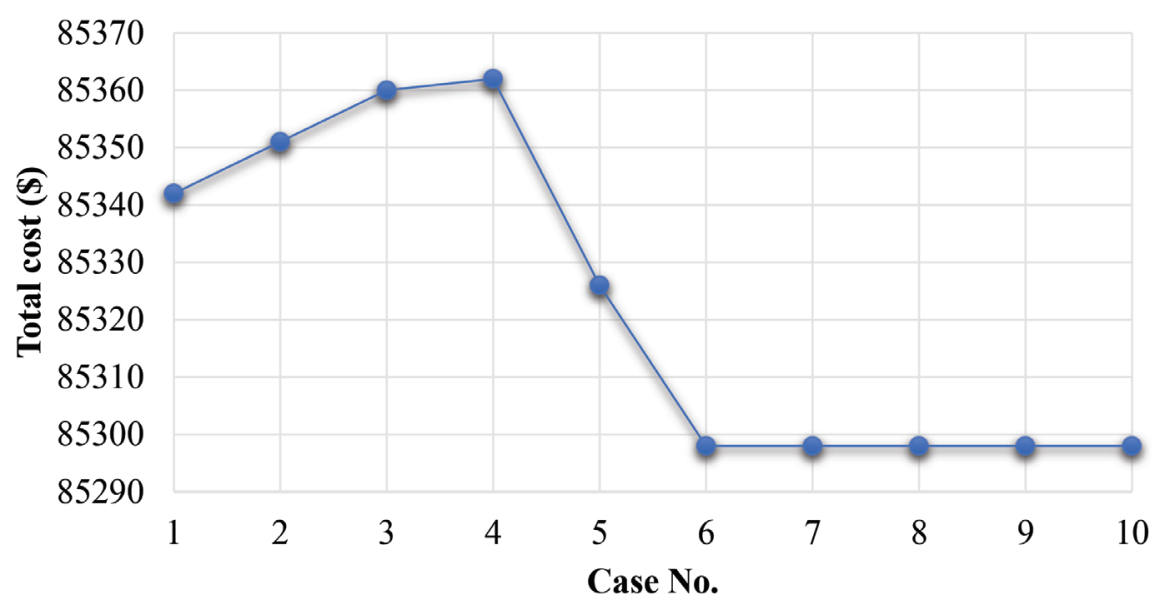

Figure 4 The impact of flow ranges of products on the total cost.

facilities and are then stocked in the warehouses for some time and then from the warehouses the products are delivered to the demand points. The warehouse location has an impact on the total cost of the supply chain network. Warehouses must be located in such a location which is close to both the production facilities as well as to the demand points. The gravity location models are also used to find the location of the warehouses that minimize the cost of transporting finished products from production facilities and then the same finished products to the market served.

Stocking products in the warehouses increases the inventory cost. Hence, the lesser the stocking time in a warehouse, lesser is the inventory cost. If the existing warehouses cannot have sufficient capacities to stock the products then rented warehouses are used to stock the products. In Figure 2, the warehouse at node 3 is owned warehouse and the warehouse at node 4 is rented warehouse.

Ten cases have been solved to analyze the impact of the stocking capacities of warehouses on the total cost. All the cases are solved for 20 working hours per day and 25 working days per month. The production rates, stocking capacities, operating costs, fixed costs and customer demands are same as shown in Figure 2. Also, the distances between the different nodes, traffic factor values and transportation costs are considered same as in Table 2 above. In all the cases considered, there is enough budget to cover all the expenses. The demand time from the customer to deliver the finished products is 25 working days. Table 5 shows the stocking capacities of the owned and rented 
Table 5 Stocking capacities of warehouses

\begin{tabular}{ccccc}
\hline \multirow{2}{*}{ Case No. } & Product & \multicolumn{2}{c}{ Capacity of Warehouse } & \\
\cline { 3 - 4 } & Owned & Rented & Total Cost (\$) \\
\hline \multirow{2}{*}{2} & A & 200 & 250 & 89409 \\
& B & 180 & 200 & \\
3 & A & 225 & 275 & 89049 \\
& B & 200 & 220 & \\
& A & 250 & 300 & 88689 \\
4 & B & 220 & 240 & \\
& A & 275 & 325 & 88308 \\
5 & B & 240 & 260 & \\
& A & 300 & 350 & 87785 \\
6 & B & 260 & 280 & \\
& A & 325 & 375 & 87269 \\
7 & B & 280 & 300 & \\
& A & 350 & 400 & 86757 \\
8 & B & 300 & 320 & \\
& A & 375 & 425 & 86385 \\
9 & B & 320 & 340 & \\
& A & 400 & 450 & 86067 \\
10 & B & 340 & 360 & \\
& A & 425 & 475 & 85349 \\
\hline
\end{tabular}

warehouses and its impact on the total cost. The discounts offered for the different ranges of products by the two shipping firms are considered the same as in Table 3 above.

It is clear that with the increase in stocking capacities of the warehouses, the total cost decreases. As the stocking capacities are increased, more products are stocked and the inventory cost also increases. Figure 5 shows the impact of the stocking capacities of warehouses on the total cost of the supply chain network.

Both the shipping firms are involved in the delivery of products to the desired nodes. With changes in the capacities of the warehouses, the assignment of products also changes. When the capacity of the owned warehouse becomes greater than the total customer demand then the rented warehouse is not used anymore.

\subsection{The Impact of Traffic Factor Values on the Total Cost}

Traffic factor values on the supply routes affects the total cost of the supply chain network. Road repair, slopes and curves, fog, military and police check 


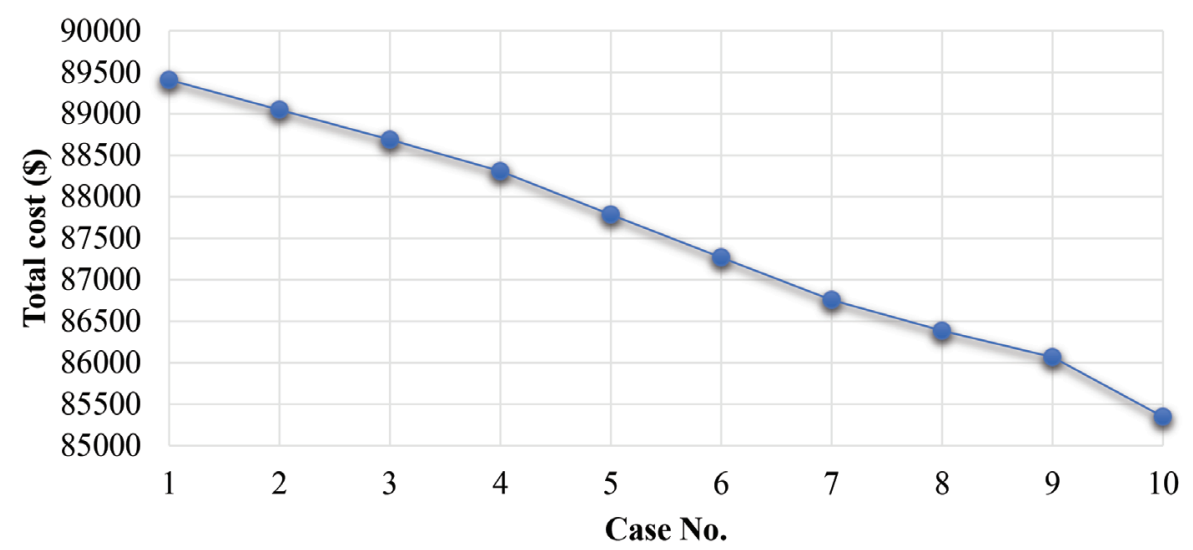

Figure 5 The impact of stocking capacities of warehouses on the total cost.

posts etc. reduces the traffic factor values on the supply routes. A closed route has traffic factor value equal to zero. A shipping firm charges more for less traffic factor values on the supply routes. A route with greater traffic factor value is preferred as it decreases the delivery time. Also, less traffic factor value results in an inconvenient delivery of products to the desired destinations. Ten different cases are solved for different traffic factor values on the supply routes and the results are shown in Table 6.

In Figure 6, the results of all cases are plotted. It is clear that with the increase in the traffic factor values, the total cost decreases. Hence, it is better to select a route with less or no hurdles.

Various factors affect the total cost of the supply chain network. With the increase in production capacities of the production facilities, less number

Table 6 The impact of traffic factor values on total cost

\begin{tabular}{cllllllllc}
\hline Case No. & $T_{13}$ & $T_{14}$ & $T_{23}$ & $T_{24}$ & $T_{35}$ & $T_{36}$ & $T_{45}$ & $T_{46}$ & Total Cost (\$) \\
\hline 1 & 0.85 & 0.86 & 0.87 & 0.88 & 0.89 & 0.90 & 0.91 & 0.92 & 92453 \\
2 & 0.86 & 0.87 & 0.88 & 0.89 & 0.90 & 0.91 & 0.92 & 0.93 & 91737 \\
3 & 0.87 & 0.88 & 0.89 & 0.90 & 0.91 & 0.92 & 0.93 & 0.94 & 91040 \\
4 & 0.88 & 0.89 & 0.90 & 0.91 & 0.92 & 0.93 & 0.94 & 0.95 & 90356 \\
5 & 0.89 & 0.90 & 0.91 & 0.92 & 0.93 & 0.94 & 0.95 & 0.96 & 89688 \\
6 & 0.90 & 0.91 & 0.92 & 0.93 & 0.94 & 0.95 & 0.96 & 0.97 & 89033 \\
7 & 0.91 & 0.92 & 0.93 & 0.94 & 0.95 & 0.96 & 0.97 & 0.98 & 88392 \\
8 & 0.92 & 0.93 & 0.94 & 0.95 & 0.96 & 0.97 & 0.98 & 0.99 & 87771 \\
9 & 0.93 & 0.94 & 0.95 & 0.96 & 0.97 & 0.98 & 0.99 & 1.00 & 87157 \\
10 & 0.94 & 0.95 & 0.96 & 0.97 & 0.98 & 0.99 & 1.00 & 1.00 & 86554 \\
\hline
\end{tabular}




\section{Razaullah et al.}

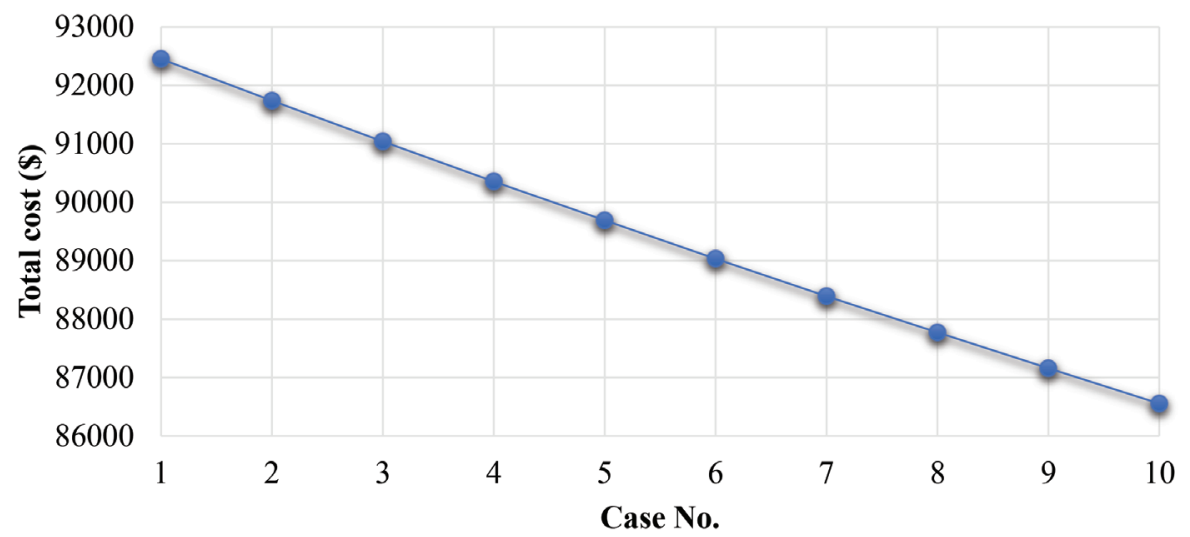

Figure 6 The impact of traffic factor values on total cost.

of production facilities are required to produce the total customer demand. Minimizing the number of production facilities minimizes the fixed costs and hence the total cost of the supply chain network. When a shipping firm delivers more products to the desired locations, less number of shipping firms are required and greater discount is offered by the shipping firm. When greater discount is offered by a shipping firm, less will be the transportation cost and hence less will be the total cost. When a shipping firm delivers less number of products in a given time, less discount is received from the shipping firm and more shipping firms are required for the delivery of products. When the owned warehouses have less capacity to stock the products, then some rented warehouses are used to stock the products. When the capacities of the owned warehouses are increased, there will be no need of to use rented warehouses and hence the total cost is decreased with increasing the capacities of the owned warehouses. With the increase in hurdles on the supply routes, the traffic factor values also decrease and results in an inconvenient delivery of products to the customers and the shipping firms charges more. When there are no hurdles on the supply routes, easier is the delivery, less is the shipping charges and less is total cost of the supply chain network. The total cost increases as the traffic factor values on the supply routes decreases.

\section{Conclusion}

The factors considered in the mathematical model formulation affects the total cost and design of the supply chain network. Greater the production capacity of a production facility, less is the total cost. Similarly, greater the stocking 
capacity of a warehouse, less is the total cost of the supply chain network. More the number of products assigned to a shipping firm, greater is the discount availed, less is the total cost. Also, maximum the traffic factor value on the supply routes of the network, less is the total cost of the supply chain. Hence, it is suggested to increase the production and stocking capacities of the facilities, select a shipping firm with greater capacity of product delivery, and select a route with less or no hurdles.

It is valuable to extend multi-objective optimization models to consider environmental objectives such as reduction of waste, emission from transport vehicles etc. in addition to the total cost. It will be useful to examine the effects of uncertainty on the model by other methods such as robust optimization and compare the results. In addition, not only uncertain demand and return may be considered, but also uncertainty in other factors such as costs should be taken into account.

\section{References}

[1] Kozlenkova, I. V., Hult, G. T. M., Lund, D. J., Mena, J. A., and Kekec, P. (2015). The role of marketing channels in supply chain management. J. Retail. 91:586-609.

[2] Slack, N., Chambers, S., and Johnston, R. (2009). Operations and Process Management: Principles and Practice for Strategic Impact. London, UK: Pearson Education.

[3] Klibi, W., and Martel, A. (2012). Scenario-based supply chain network risk modeling. Eur. J. Oper. Res. 223:644-58.

[4] Altiparmak, F., Gen, M., Lin. L., and Karaoglan, I. (2009). A steadystate genetic algorithm for multi- product supply chain network design. Comput. \& Ind. Eng. 56:521-37.

[5] Lee, B. K., Kang, K. H., and Lee, Y. H. (2008). Decomposition heuristic to minimize total cost in a multi- level supply chain network. Comput. \& Ind. Eng. 54:945-59.

[6] Nagurney, A. (2010). Optimal supply chain network design and redesign at minimal total cost and with demand satisfaction. Int. J. Prod. Econ. 128:200-8.

[7] Lashine, S. H., Fattouh, M., and Issa, A. (2006). Location/allocation and routing decisions in supply chain network design. J. Model. Manag. $1: 173-83$.

[8] Pettersson, A. I., and Segerstedt, A. (2013). Measuring supply chain cost. Int. J. Prod. Econ. 143:357-63. 
[9] Vidal C. J., and Goetschalckx, M. (2001). A global supply chain model with transfer pricing and transportation cost allocation. Eur. J. Oper. Res. 129:134-58.

[10] Nagurney, A., Liu, Z., and Woolley, T. (2007). Sustainable supply chain and transportation networks. Int. J. Sustain. Transport. 1:29-51.

[11] Xiao, Y., Chen, J. (2012). Supply chain management of fresh products with producer transportation. Decis. Sci. 43:785-815.

[12] Cui, L., Wang, L., Deng, J., and Zhang, J. (2015). Intelligent algorithms for a new joint replenishment and synthetical delivery problem in a warehouse centralized supply chain. Knowl. Based Syst. 90:185-98.

[13] Miranbeigi, M., Moshiri, B., Rahimi-Kian, A., and Razmi, J. (2015). Demand satisfaction in supply chain management system using a full online optimal control method. Int. J. Adv. Manu. Tech. 77:1401-17.

[14] Dubey, V., and Veeramani, D. (2017). A framework for sizing an automated distribution center in a retail supply chain. Simul. Model. Pract. Theory 75:113-26.

[15] Matsui, K. (2016). Asymmetric product distribution between symmetric manufacturers using dual-channel supply chains. Eur. J. Oper. Res. 248:646-57.

\section{Biographies}

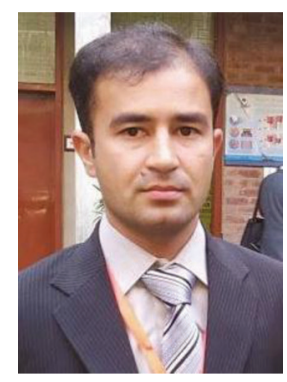

Razaullah received his $\mathrm{PhD}$ degree from University of Engineering and Technology, Peshawar, Pakistan in the year 2017 and is assistant professor in Sarhad University of Science and Information Technology, Peshawar, Pakistan. Razaullah received his BSc degree in Mechanical Engineering in the year 2009 and then MSc degree in Industrial Engineering in 2013 from University of Engineering and Technology, Peshawar, Pakistan. He also worked as operational and maintenance engineer in a telecommunication company. His MSc research was trim loss minimization and reel cutting at 
a paper mill and $\mathrm{PhD}$ worked centered on the design of supply chain networks for product distribution of a manufacturing industry.

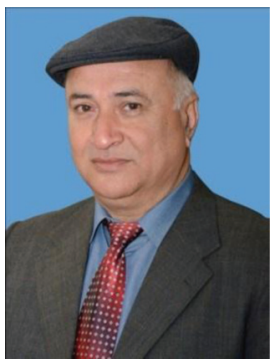

Iftikhar Hussain is a professor in industrial engineering and vice chancellor of University of Engineering and Technology, Peshawar, Pakistan. Before taking the vice chancellor position, he was chairman of the department of industrial engineering for 10 years. Dr. Iftikhar Hussain has been elected member of the executive council of Pakistan Engineering Council, Pakistan in 2015. He graduated with a first class special honors in mechanical engineering and then undertook his $\mathrm{PhD}$ in flexible manufacturing at University of Bradford, United Kingdom. Dr. Iftikhar Hussain has published numerous research papers and edited several books. He has served on many editorial boards of international and national journals of well repute. Dr. Iftikhar's research has been published in textbooks and in many popular science journals.

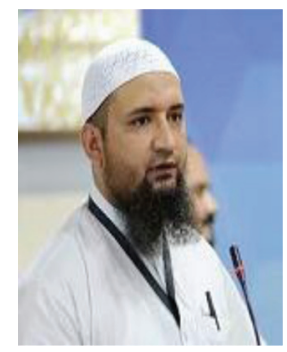

Shahid Maqsood is associate professor in industrial engineering and chairman department of Industrial Engineering, University of Engineering and Technology, Jalozai Campus, Peshawar, Pakistan. He graduated with a first class special honors in mechanical engineering and then undertook 


\section{Razaullah et al.}

his MS in Mechanical Engineering from GIK Institute, Sawabi, Pakistan. Dr. Shahid Maqsood then received his $\mathrm{PhD}$ degree from University of Bradford, United Kingdom. Dr. Shahid Maqsood has published numerous research papers and edited several books. His research interests span both engineering optimization and computer integrated manufacturing.

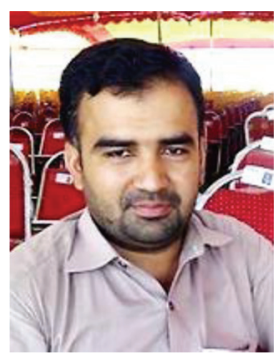

Ishtiaq Ahmad is received his BA degree from University of Peshawar, Peshawar, MBA degree in Finance from Iqra National University, Peshawar and MS degree in Management Sciences degree from Abasyn University, Peshawar. Currently, he is PhD Management Sciences student at Iqra National University, Peshawar. He is working as assistant account officer at University of Engineering and Technology, Peshawar, Pakistan. He also worked as visiting lecturer in local institutions. His research area is management sciences. 